\title{
Omnichannel Retail Customer Experience with Mixed-Reality Shopping Assistant Systems
}

\author{
Shubham Jain $\left.{ }^{(}\right)$, Thomas Schweiss, Simon Bender, and Dirk Werth \\ August-Wilhelm Scheer Institute, Saarbrücken, Germany \\ \{thomas.schweiss, simon. bender, dirk.werth\} @aws-institut.de
}

\begin{abstract}
Mixed reality has been identified as one of the technologies that can be deployed in omnichannel retail to improve the customer shopping experience. The article presents a mixed reality based digital shopping assistant which aims to provide retail customers with a holistic shopping experience. Design science research methodology is used to develop this physical artifact that comprises of assisting elements: product information, reviews, recommendations and a buy button. A study was conducted with two different head-mounted displays (Microsoft HoloLens and HoloLens 2) where 29 participants evaluated the proposed physical artifact and brings out the relationship between shopping experience constructs that constitutes a modern omnichannel retail customer experience. Results show a positive attitude of customers towards the technology. Differences between the two-head mounted displays were observed in terms of perceived privacy issues. Technology adoption, enjoyment and security beliefs of the customers are observed to have a significant effect on the user's intention to use the technology. The results also reveal that a customer's perceived convenience, perceived service quality, attitude towards the retailer and the word of mouth are affected significantly by their intention to use the technology. These results, along with qualitative comments from the participants are used to extract research, development and deployment implications for future iterations of shopping assistant systems based on mixed reality.
\end{abstract}

Keywords: Mixed reality · Omnichannel retail - Digital retail $\cdot$ Customer experience

\section{Introduction}

The concept of 'omnichannel retail' is centered around providing customers with a holistic shopping experience [1]. It has been established as the next step to digital retail [2] that makes it important for the retailers to stay relevant in the business. Several retailers have already started with this transition to omnichannel and have benefited from it [3]. Omnichannel retail has also been suggested as one of the tools to battle the 'retail apocalypse' [4], and consequently meet the expectations of a progressive retail customer. Along with this, research around digital and omnichannel retail has become more important as a consequence of COVID-19 where traditional retail environments are forced to adopt newer models and technologies [5].

(C) The Author(s) 2021

G. Bebis et al. (Eds.): ISVC 2021, LNCS 13017, pp. 504-517, 2021.

https://doi.org/10.1007/978-3-030-90439-5_40 
An omnichannel customer expects their shopping journey to be seamless and attributed with utilitarian and hedonic values, while they evaluate their shopping experience by interacting with the shopping environment [1]. One of the key attributes of an omnichannel retail environment is the optimal deployment of novel digital technologies like digital realities, smartphones and recommender systems to enhance the customer's shopping journey [6]. Among these technologies, Mixed Reality (MR) has emerged as one of the key technology megatrends that has the potential to revolutionize the retail sector in the next decade [7]. MR has a unique capability to bridge the gap between online and offline environments which fits right into the concept of omnichannel retail where multiple channels are integrated into a single seamless customer journey. Furthermore, a shopping assistant system that leverages the qualities of MR technology to tackle customers' needs and improve their experience is one of the preeminent ways to row through the transition to omnichannel retail [8].

Design Science Research (DSR) methodology can be used to develop such systems, as it provides a rigid framework to produce physical artifacts that can solve real-world organizational problems [9-11]. This is an iterative approach where the evaluation of the physical artifact is an important step to optimize the next iteration. Traditionally, Technology Acceptance Model (TAM) [12] has been used in this regard to capturing user perception over innovative technologies. While the literature advances, a number of authors have manifested TAM to fit better into their particular context, for e.g., the authors in [13] added the hedonic element 'enjoyment' to their studies. Other constructs like user's privacy and trust have also been studied to influence the perception of retail customers as they emerge as a topic of concern in the current literature [14]. These factors can influence the customer's overall perception of retail technologies which can affect different shopping outcomes for retailers and their businesses.

Although the present literature brings out a lot of different advantages of MR, and several application designs towards retail [15], more research is required towards the understanding of user's perception towards the technology. This is the targeted research gap, which also builds upon the research framework mentioned in [16]. Towards this, we firstly use DSR to design an omnichannel retail shopping assistant system using 'optical see-through mixed reality' and Microsoft (MS) HoloLens and Microsoft HoloLens 2 as two different hardware archetypes. We use the present industry and academic standards to develop a pseudo-optimal system, hence contributing a physical instantiation as the research outcome.

Furthermore, we captured user perception towards the designed artifact in a laboratory study with 29 participants. An extended TAM was used to study users' behavioral intentions. The results reveal the relationship between the different shopping constructs. These results along with the qualitative comments from the participants during the study are used to extract research, development and deployment implications. These implications aim to contribute towards a better understanding of the general user perception towards MR-based retail systems and suggest improvements over the next iteration of the prototype. Hence, we add to the current literature of MR systems in retail environments. 


\section{Background and Previous Work}

\subsection{Optical-See Through Mixed Reality}

The 'Virtuality continuum' defined by Paul Milgram [17] categorizes optical see-through mixed reality (OSTMR) as class 3 displays. These devices are "head-mounted displays equipped with a see-through capability, with which computer-generated graphics can be optically superimposed" [17, p. 3]. As there is limited literature on the deployment of OSTMR in retail, we first reviewed some literature from similar technologies. For example, Authors in [18] and [15] deployed smartphone-based MR applications that aim to enhance the in-store shopping experience. However, smartphones are limited in terms of providing a natural posture for interaction and communicating tangible characteristics of a product to the customer. Other devices like Oculus [19], which uses the concept of fully immersive virtual reality (VR) also has been studied in this regard. Fully immersive VR poses a challenge for customers as it occludes the vision of a user and hence, obstructs their primary tasks in a natural environment. Also, non-immersive technologies like display screen monitors have been used in this regard to develop physical artifacts for an enhanced customer journey. A 2D display like a monitor screen or a smartphone is unable to project an organic environment even with touch and sensor-based input methods. These technologies have proven their significance for a long time but still is abstain from providing hedonism and natural interactions [20]. OSTMR complements these technologies by having the capability of not completely occluding the vision of a user during the use, and creating a pseudo immersive environment where digital and physical objects co-exist and interact with each other. This makes the experience more tangible, interactive, and exciting for customers as compared to other display and interaction technologies. MS HoloLens executes this task using a holographic display that projects 'holograms', which are digital objects rendered into the real world. These holograms are enhanced by sound and light and can be interacted with, using interaction techniques provided by the device [21].

\subsection{MR Shopping Assistant System}

A contemporary customer has high expectations in terms of their shopping experience due to the development of technologies. Retailers need to address these needs and expectations to stay relevant in the business [22]. This can be done by providing personalized and tailored assistance with digital shopping assistants [7]. Personal MR devices can provide this assistance putting the customers in control of their shopping journey and helping them towards comparing products, finding alternatives, and feeling more confident in their decision-making at the purchase. Previous authors have used OSTMR to develop such systems in different settings. Recent literature shows examples such as [23] where the authors used this technology to develop an in-store recommender system that can provide tailored recommendations to customers. Other examples brought out features like product detection [24] and Natural User Interaction (NUI) [25] that can be used in an optimal MR shopping assistant design. Authors in [26] suggest the use of product information and reviews in a shopping assistant system while mentioning the importance of hardware design. Authors in [27] point out the significance of the 'buy' 
button in a shopping interface. Collectively, these shopping elements and MR features can help design a pseudo-optimal MR shopping assistant system.

\subsection{Customer Experience and Hypotheses Development}

Customer experience is considered to be the center of omnichannel retail business models [2]. It has been defined to be "holistic in nature and involves the customer's cognitive, affective, emotional, social and physical responses to the retailer" [28, p. 70]. Thus, it is absolutely important to understand customers' perceptions and responses in order to create digital solutions towards enhancing their shopping journey [1]. The customer experience can consist of a plethora of constructs that can be based on subjective and objective attributes. The current work does not aim to report an exhaustive account of all the customer experience constructs but works on a set of constructs that have been either studied extensively in academic literature or are relevant in the current age. One of the most used models to test the usability, and capture the user perception towards a new technology-based system is TAM (Davis 1985), which predicts the user's Intention to use (ITU) a system using 'Perceived usability' (PU), and 'Perceived ease of use' (PEOU). PU and PEOU are collectively used to define 'technology adoption' in the current work. Along with the utilitarian assistance provided by the desired solution, hedonic motivations such as fun, pleasure, and enjoyability [29] are crucial factors influencing customers' shopping experience. 'Enjoyability' has been used as an added parameter of technology adoption [30, 31], even especially for MR [32], where the authors bring out the importance of the construct and its positive effect on factors like purchase intention and the attitude of the customers in a shopping journey. Developing on these findings, we propose the first hypothesis:

\section{H1: Perceived usefulness (H1a), perceived ease of use (H1b), and perceived enjoyment (H1c) have a significant effect on the intention to use the MR shopping assistant in omnichannel retail.}

'Security beliefs' consisting of 'Privacy concerns' and 'Trust' are adapted from [26]. The authors argued that trust and privacy concerns play an important role in the general perception of the shopping environment and whether customers will use the technologies or not. The authors used two shopping assistance systems that leverage either bar-code scanner or radio frequency identification (RFID) reader as the hardware design, while we want to study the effects in MR technology. The authors in [14] state that security concerns have risen with technologies like MR, which can affect the customer perception in a retail environment. Hence, we propose the second hypothesis as:

\section{H2: Privacy concerns (H2a) and trust (H2b) have a significant effect on the intention to use the MR shopping assistant in omnichannel retail.}

Shopping outcomes comprise of 'Convenience', 'Word-of-mouth', 'Attitude towards a retailer', and 'Customer service quality' [26]. These outcomes are some of the widely studied constructs in context to customer experience and perception [33-35]. These constructs have been mentioned in the literature to have a great impact on the retailer's 
businesses, and hence are important to be researched. As digital technology is an important part of an omnichannel retail environment, we believe that the intention to use the system can shape these outcomes. Hence, we propose the following hypothesis.

H3: The intention to use the MR shopping assistant in omnichannel retail has a significant effect on the shopping outcomes: Convenience (H3a), Word-of-mouth $(\mathrm{H} 3 b)$, Customer service quality $(\mathrm{H} 3 \mathrm{c})$ and Attitude towards a retailer $(\mathrm{H} 3 \mathrm{~d})$.

\section{MR Shopping Assistant System}

The designed system is summarized below using the eight components of the information systems design science principles mentioned in [9].

Purpose and Scope: The mixed-reality digital shopping assistant application was designed to provide customers with an exciting and helpful shopping journey.

Constructs: Technology adoption (perceived usefulness, perceived ease-of-use), intention to use, enjoyment, security beliefs (privacy concerns, trust), shopping outcomes (convenience, word-of-mouth, customer service quality, attitude towards a retailer).

Principle of Form and Function: The blueprint of the IT artifact involved hardware and software design:

Hardware Design (MS HoloLens and MS HoloLens 2): The produced artifact in the form of a digital shopping assistant is deployed over two different OSTMR devices of the same family: MS HoloLens and HoloLens 2. The first generation of MS HoloLens introduced a whole new ecosystem of immersive technology devices and was projected as the 'The future of augmented reality' [21]. Despite its success as a developer prototype, certain limitations of the hardware were reported like the narrow field of view, the complexity of interaction methods, ergonomics, etc. The second generation, HoloLens 2 brings several improvements for the first-generation device such as a dedicated DNN core, wider field of view, improved ergonomics, articulated hand tracking, and eye gaze tracking [36]. Both devices aim to deploy a multimodal NUI based on hand gestures and voice interaction, but HoloLens 2 claims to have a more natural interaction as the digital holograms can be 'touched' like physical objects as compared to the 'gaze and commit' scheme of HoloLens. However, the shortcomings of the earlier device can be compensated by using the HoloLens Clicker, which is a handheld click-based interaction device, which reduces the physical complexity of the HoloLens interaction schema. Arguably, this reduction in the physical complexity of interaction can take over the reward of naturalness in HoloLens 2. This will lead to a similar perception for both of the devices which also implies higher scalability of the designed interface.

Software Design (Information, Recommendation, Reviews, and a Buy Button). The system largely builds over the requirements developed by the authors in [23]. We deployed image recognition using Vuforia Engine [37] that enables the system to detect the product of interest that is brought on to its field of view (FOV). Once the device recognizes 

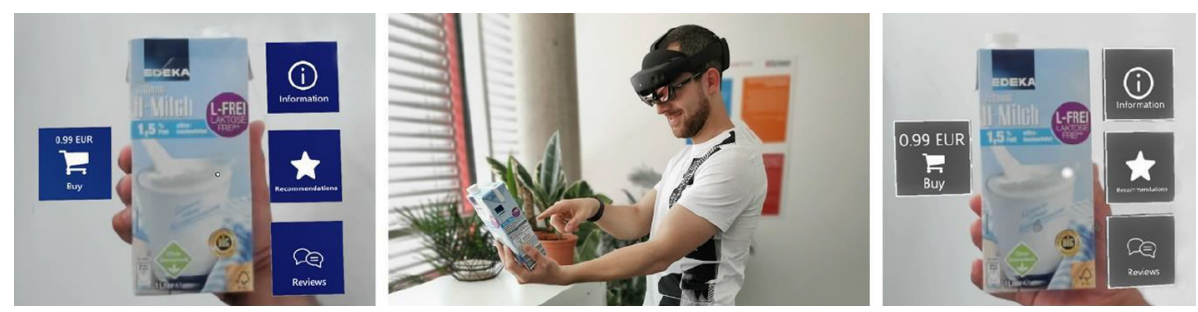

Fig. 1. Application design: HoloLens 2 (left), HoloLens (right); Participant interacting with the application (center)

the product, a 3D digital interface is placed around the object as shown in Fig. 1 (left and right).

The interactive user interface is designed with the help of standardized tools: Mixed Reality Toolkit (MRTK and MRTK2) for HoloLens 1 and HoloLens 2 [38]. The UI contains four major elements: 'Information,' 'Recommendations,' 'Reviews,' and 'Buy' as shown in Fig. 1. These elements are represented as 3D buttons that are anchored on to the product. Information and reviews, as a shopping assistant element has been adapted from $[26,39]$ where the combination of these two elements in the artifact was preferred by the customers in comparison to the absence of them or presence of only one of the elements. Mining data from different channels to provide a customized service such as product recommendations on ubiquitous devices, such as the HoloLens could create multiple benefits in the retail ecosystem [40]. For retail customers, the product recommendations boost the efficiency in finding preferential products, provide more confidence in making a purchase decision, and give a potential chance to discover something new. These assistance items aim to reduce information overload and enhance decision-making [41] as the customer is more confident in the buying process. Furthermore, it was necessary to introduce a one-click checkout UI item [42], following web-based shopping interfaces. This is addressed with the 'Buy' button in the UI, which eases the customer's path-topurchase and target the customer's need to buy the product immediately, raising customer satisfaction, solving the 'crisis of immediacy' [22], and integrating the customer journey into one channel/touchpoint. Both devices are rigged with a voice recognition system which can be used by the user to disable or enable the holograms attached to the product by saying 'start' and 'stop' respectively.

Artifact Mutability: The artifact designs were developed toward scalability. Although during the tests, the application content was static, a retailer's databases could be linked to the artifacts. By having access to real-time data, the artifacts could adjust to the dynamic retail environment.

Testable Propositions: Nine prepositions were constructed based on the present literature (see Sect. 2).

Justificatory Knowledge: Drawing on existing literature, generalizations were constructed from patterns observed in academic literature and industry trends.

Principles of Implementation: Several recommendations for implementing the learnings in future research and iterations are provided in the form of implications. 
Expository Instantiation: The MR shopping artifacts were implemented in a simulated omnichannel retail environment.

\section{Experiment Setup}

The study was conducted with 29 participants who tried the MR application on both devices (HoloLens, HoloLens 2). The participants were recruited using e-mail and instant message-based invitations. The order of the devices was randomized and distributed evenly among the population. Sixteen $(55 \%)$ of the participants were male while the other $45 \%$ were female. The participants were from ten different nationalities, however, $17(59 \%)$ were German. The mean age of the participants was 28 years with a standard deviation of 4.8. Eighteen (62\%) of the participants answered "yes" to the question "Have you had any experience with Mixed-Reality before this study?", and hence had prior experience with MS HoloLens or similar immersive environments. The participation was voluntary, and no financial compensation was provided.

An omnichannel retail environment was simulated in a laboratory with a hypothetical retailer 'AWS'. The setting consisted of two different categories of products that are considered to diversify the product assortment in the setting: Search products (a pack of milk, a computer monitor, a pair of sneakers, a package of soft-drinks, a pack of coffee beans) and experience products (i.e., a box of chocolate, a tech magazine, a bottle of rum, a video game disc, a 6-pack of beer).

The setup was made to look casual, and less like a traditional brick-and-mortar store. Written consent was obtained from the participants which was followed by a short introduction to the application and the environment. Then, the participants were assigned the task of 'general browsing' where they were asked to browse and buy the available products as they want. This was done using verbal and written instructions. No real money was involved in the buying process and the task was more oriented towards testing the functionalities of the application and experiencing the shopping environment. General browsing was chosen over goal-oriented because the goal of the study focused more on a participant's perception and opinion about technology and less on the efficiency of the application during the shopping journey. The participants were then asked to complete a questionnaire that consisted of 34 items. They rated their responses on a 7point Likert Scale. Scales were adopted from [26] for technology adoption, intention to use, security beliefs, and customer shopping outcomes. Items in the scale for enjoyability were adopted from $[13,32]$. The complete questionnaire is attached in the appendix Table A1. The study took less than 60 min per participant with an exposure of approximately $30 \mathrm{~min}$ to the MR devices ensuring that there is no simulation sickness to deviate the user's opinion towards the technology. 


\section{Results}

The scales' reliability was tested, and the cronbach's alpha was greater than 0.90 with both the devices, hence making the scale reliable. Table 1 summarizes the participants' response towards the technology, with both the hardware devices. Paired t-test was used to compare the two hardware and the results show a significant difference between the perceived privacy concerns in HoloLens (HL1) and HoloLens 2 (HL2). As a higher value with privacy concerns means fewer privacy concerns (see Table A1), it can be interpreted that the participants felt more comfortable with HoloLens 2 towards their privacy.

Table 1. Mean and Standard deviation (SD) for HoloLens1 and HoloLens 2

\begin{tabular}{|c|c|c|c|c|c|}
\hline Construct & Mean (HL1) & SD & Mean (HL2) & $\mathrm{SD}$ & P-value with paired t-test \\
\hline Intention to use & 5.21 & 1.59 & 5.44 & 1.11 & 0.17 \\
\hline $\begin{array}{l}\text { Perceived } \\
\text { usefulness }\end{array}$ & 5.23 & 1.23 & 5.31 & 1.15 & 0.35 \\
\hline $\begin{array}{l}\text { Perceived ease of } \\
\text { use }\end{array}$ & 5.56 & 1.36 & 5.35 & 1.01 & 0.25 \\
\hline Enjoyability & 5.68 & 1.31 & 5.98 & 0.93 & 0.16 \\
\hline Privacy concerns & 4.42 & 1.22 & 4.70 & 1.20 & 0.04 \\
\hline Trust & 4.61 & 0.71 & 4.65 & 0.67 & 0.39 \\
\hline Convenience & 5.05 & 0.99 & 5.21 & 0.94 & 0.23 \\
\hline Word-of-mouth & 5.53 & 1.14 & 5.52 & 1.08 & 0.48 \\
\hline $\begin{array}{l}\text { Customer service } \\
\text { quality }\end{array}$ & 5.15 & 1.22 & 5.14 & 1.28 & 0.48 \\
\hline $\begin{array}{l}\text { Attitude toward the } \\
\text { retailer }\end{array}$ & 5.56 & 1.25 & 5.76 & 1.04 & 0.21 \\
\hline
\end{tabular}

\subsection{Regression Analysis}

The Hypotheses proposed in Sect. 2 were tested using linear regression analysis. The regression coefficient was calculated along with the significance (p-values) of the relationships. Figure 2 presents the results from the analysis. The hypotheses are tested with the criteria that if $\mathrm{p}<0.05$, the null hypothesis can be rejected and the proposed hypothesis is supported. The results show that perceived usefulness, perceived ease of use and enjoyment has a significant effect on the intention to use, thus supporting H1a-c. The results also show a significant effect of privacy concerns and trust on intention to use with both hardware even though privacy concerns have a higher effect in the case of HoloLens 2. Also, intention to use is seen to have a significant effect on all the shopping outcomes (convenience, word-of-mouth, customer service quality and attitude towards a retailer). Hence, $\mathrm{H} 2 \mathrm{a}-\mathrm{b}$ and $\mathrm{H} 3 \mathrm{a}-\mathrm{d}$ are fully supported. 


\begin{tabular}{|c|c|c|c|c|c|c|}
\hline Perceived Usefulness & $0.75^{* * *}$ & H1a & \multirow{7}{*}{$\begin{array}{l}\text { Intention } \\
\text { to Use }\end{array}$} & $0.60^{* *}$ & H3a & Convenience \\
\hline Perceived Fase of Jse & $0.40^{*}$ & H1b & & $0.65^{* *}$ & $\mathbf{H} 3 \mathbf{b}$ & \\
\hline & \multirow{2}{*}{\multicolumn{2}{|c|}{$0.60^{* * *} \quad \mathrm{H} 1 \mathrm{c}$}} & & & & Word-of-mouth \\
\hline Enjoyment & & & & $0.80 * *$ & $\mathrm{H} 3 \mathrm{c}$ & \\
\hline Driyacy Concornc & \multicolumn{2}{|c|}{ HL1: $0.44^{*} /$ HL2: $0.49^{* *}$ H2a } & & 0.00 & & Customer Service Quality \\
\hline Privacy concerns & \multirow{2}{*}{\multicolumn{2}{|c|}{$0.44^{*} \quad$ H2b }} & & & $\mathrm{H}_{3} \mathrm{~d}$ & \\
\hline Trust & & & & 0.12 & 113a & Attitude towards a retailer \\
\hline
\end{tabular}

Fig. 2. Hypotheses testing using simple linear regression, Note: $* \mathrm{p}<.05$, ** $\mathrm{p}<.01$, *** $\mathrm{p}<$ .001

\subsection{Qualitative Comments from the Participants}

During the study, the participants were allowed to make comments and ask questions about the use of the prototype. As HoloLens and HoloLens 2 are not designed in the current age to be used by naïve customers, participants mentioned a number of ergonomic issues with the hardware. This was observed with both devices in terms of heaviness and general comfort. The participants also mentioned interaction and visualization problems, for e.g., the clipping of 3D objects in the case of HoloLens. The users responded positively towards the overall usability of the interface and made some suggestions for the next iteration. This includes changing the 'one-touch' buying mechanism to a more secure virtual cart-based process that gives them a chance to review the products before the payment. Another suggestion was made to add meta-information elements that are either unique to an MR experience, or that combine online e-commerce and the traditional brick and mortar retail environment.

\section{Discussion and Implications}

The quantitative results along with the qualitative comments from the participants can have several implications for future research and development. The quantitative results in Table 1 show a positive reaction towards the MR shopping assistant system, while the quantitative comments suggest improvement over the next iteration of the prototype. The implications from these results are as follows:

\section{Research Implications}

- As participants made valuable suggestions and comments during the quantitative study, we motivate researchers to follow a mixed-method research method that aims to qualitatively triangulate the quantitative findings to confirm and expand the knowledge and causes of the proposed hypothesis [43].

- Following simple linear regression, multiple linear regression and mediation analysis should be used to better model the omnichannel retail customer experience in MR environments.

- With HoloLens 2, participants showed fewer concerns towards privacy issues which calls for further privacy research with mixed reality environments. 


\section{Development Implications}

- Virtual shopping carts should be used in an MR shopping assistance system to facilitate shopping for customers.

- Developers should highlight the novelty of MR environments by integrating shopping assistant elements that provide unique value to the customers. This can be done by integrating online and offline elements into a single application.

- An MR shopping assistant application should focus on the efficiency of interactions and the effects of visualization. This can be done by either iterating the prototypes repeatedly using subjective evaluations or providing an option to tailor the user interface according to the customer's needs.

\section{Deployment Implications}

- MR shopping assistant systems are constrained by a number of constructs. These include technology adoption constructs (PU, PEOU), enjoyability privacy concerns and trust among others that can influence the intention to use the technology, which further affects a customer's perceived convenience, word-of-mouth towards the retailers, perceived service quality and attitude towards the retailer.

- Even though the results suggest a positive perception of MR technology in retail, as in Table 1, the retailers should be mindful of the deployment constraints and customize their omnichannel solutions according to their business needs and customer perception.

\section{Conclusion}

In the current age where the retail sector is forced to transition into an omnichannel paradigm due to industry trends and environmental factors like COVID-19, it is important for retailers to deploy innovative retail solutions in their businesses to enhance their customer's shopping experience. In the current research, we first designed an OSTMR shopping assistant system using MS HoloLens and HoloLens 2 as the hardware archetypes. We integrated product information, reviews, recommendations, and a buy button into a $3 \mathrm{D}$ interface using the DSR approach. The evaluation of the system in a laboratory study suggests a positive perception of a user towards the technology, while several research, development and deployment implications are extracted from the quantitative results and the qualitative comments.

Acknowledgement. This research is a part of the European Training Network project PERFORM

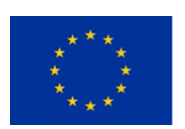
that has received funding from the European Union's Horizon 2020 research and innovation programme under the Marie Skłodowska- Curie grant agreement No. 765395. This research reflects only the authors' view, the European Commission is not responsible for any use that may be made of the information it contains. 


\section{Appendix}

Table A1. Scales Used, Note: *This item was reverse coded

\begin{tabular}{|c|c|}
\hline Item no. & Items \\
\hline \multicolumn{2}{|c|}{ Intention to use } \\
\hline 1. & I would use Mixed Reality shopping to shop in the store \\
\hline 2. & I intend to use Mixed Reality shopping the next time I see it in the store \\
\hline 3. & I will not use Mixed Reality shopping the next time I see the system in the store* \\
\hline \multicolumn{2}{|c|}{ Technology adoption } \\
\hline & Perceived usefulness \\
\hline 4. & Using Mixed Reality shopping in the store added value to my shopping experience \\
\hline 5. & The experience of using Mixed Reality shopping in the store was useful to me \\
\hline \multirow[t]{2}{*}{6.} & $\begin{array}{l}\text { I believe that the experience of using Mixed Reality shopping in the store added } \\
\text { value to the overall service }\end{array}$ \\
\hline & Perceived ease of use \\
\hline 7. & $\begin{array}{l}\text { My interaction with Mixed Reality shopping in the store was clear and } \\
\text { understandable }\end{array}$ \\
\hline 8. & It was easy for me to become skilful at using Mixed Reality shopping in the store \\
\hline 9. & I found Mixed Reality shopping easy to use in the store \\
\hline 10. & Learning to operate Mixed Reality shopping in the store was easy for me \\
\hline \multicolumn{2}{|c|}{ Enjoyability } \\
\hline 11. & Using Mixed Reality for shopping was fun \\
\hline 12. & Using Mixed Reality shopping was enjoyable \\
\hline 13. & Using Mixed Reality shopping was exciting \\
\hline
\end{tabular}

Security beliefs

\begin{tabular}{l|l}
\hline & Privacy concerns \\
\hline 14. & I feel comfortable giving personal information on this retailer \\
\hline 15. & I feel comfortable shopping at this retailer \\
\hline 16. & The retailer clearly explained how user information will be used \\
\hline 17. & Information regarding security of payments is clearly presented \\
\hline 18. & Trust \\
\hline 19. & This store is trustworthy \\
\hline 20. & I trust this store keeps my best interests in mind \\
\hline 21. & I think it makes sense to be cautious with this store \\
\hline 22. & This retailer has more to lose than to gain by not delivering on their promises \\
\hline
\end{tabular}

\section{Shopping outcomes}

\begin{tabular}{l|l}
\hline & Convenience \\
\hline 23. & It was convenient to find information on products \\
\hline 24. & I found it complicated to find products at this store* \\
\hline
\end{tabular}


Table A1. (continued)

\begin{tabular}{l|l}
\hline Item no. & Items \\
\hline 25. & It is convenient to shop from this retailer \\
\hline 26. & Word-of-mouth \\
\hline 27. & I would recommend visiting this retailer to friends \\
\hline 28. & I would say good things about this retailer to others \\
\hline 29. & I would encourage friends and relatives to visit this retailer \\
\hline 30. & Customer service quality \\
\hline 31. & The retailer's customer service was of high quality \\
\hline 32. & The retailer's customer service was always functional \\
\hline 33. & The retailer's customer service was very reliable \\
\hline 34. & Attitude towards a retailer \\
\hline
\end{tabular}

\section{References}

1. Lemon, K.N., Verhoef, P.C.: Understanding customer experience throughout the customer journey. J. Mark. 80, 69-96 (2016). https://doi.org/10.1509/jm.15.0420

2. Rigby, D.K.: The future of shopping. Harv. Bus. Rev. 89, 65-76 (2011)

3. Zhang, M., Ren, C., Wang, G.A., He, Z.: The impact of channel integration on consumer responses in omni-channel retailing: the mediating effect of consumer empowerment. Electron. Commer. Res. Appl. 28, 181-193 (2018). https://doi.org/10.1016/j.elerap. 2018.02.002

4. Berman, B.: Flatlined: combatting the death of retail stores. Bus. Horiz. 62, 75-82 (2019). https://doi.org/10.1016/j.bushor.2018.08.006

5. Shankar, V., et al.: How technology is changing retail. J. Retail. 97, 13-27 (2021). https://doi. org/10.1016/j.jretai.2020.10.006

6. Burke, R.R.: Technology and the customer interface: what consumers want in the physical and virtual store. J. Acad. Mark. Sci. 30, 411-432 (2002). https://doi.org/10.1177/009207002 236914

7. von Briel, F.: The future of omnichannel retail: a four-stage Delphi study. Technol. Forecast. Soc. Chang. 132, 217-229 (2018). https://doi.org/10.1016/j.techfore.2018.02.004

8. Competing in the age of omnichannel retailing (2013)

9. Gregor, S., Jones, D.: The Anatomy of a Design Theory, pp. 1536-9323 (2007)

10. Hevner, A.R., Chatterjee, S.: Design research in information systems. Theory and practice. In: Hevner, A., Chatterjee, S. (eds.). Forewords by Paul Gray and Carliss Y. Baldwin. Springer, New York, London (2010)

11. Peffers, K., Tuunanen, T., Rothenberger, M.A., Chatterjee, S.: A design science research methodology for information systems research. J. Manag. Inf. Syst. 24, 45-77 (2007). https:// doi.org/10.2753/MIS0742-1222240302

12. Davis, F.: A technology acceptance model for empirically testing new end-user information systems, theory and results. Doctoral dissertation, Massachusetts Institute of Technology (1985) 
13. Rasimah, C.M.Y., Ahmad, A., Zaman, H.B.: Evaluation of user acceptance of mixed reality technology. AJET 27 (2011). https://doi.org/10.14742/ajet.899

14. Pizzi, G., Scarpi, D.: Privacy threats with retail technologies: a consumer perspective. J. Retail. Consum. Serv. 56, 102160 (2020). https://doi.org/10.1016/j.jretconser.2020.102160

15. Spreer, P., Kallweit, K.: Augmented reality in retail: assessing the acceptance and potential for multimedia product presentation at the PoS. SOP Trans. Market. Res. 1(1), 23-31 (2014). https://doi.org/10.15764/MR.2014.01002

16. Jain, S., Werth, D.: Current state of mixed reality technology for digital retail: a literature review. In: Nah, F.-H., Siau, K. (eds.) HCII 2019. LNCS, vol. 11588, pp. 22-37. Springer, Cham (2019). https://doi.org/10.1007/978-3-030-22335-9_2

17. Milgram, P., Kishino, F.: A Taxonomy of Mixed Reality Visual Displays (1994)

18. Meegahapola, L., Perera, I.: Enhanced in-store shopping experience through smart phone based mixed reality application. In: Regions, I.C.o.A.i.I.f.E. (ed.) 17th International Conference on Advances in ICT for Emerging Regions (ICTer) - 2017. Conference Proceedings: 07th \& 08th of September 2017, Vidya Jyothi Prof. V. Samaranayaka Auditorium, University of Colombo School of Computing, Colombo, Sri Lanka, pp. 1-8. IEEE, Piscataway (2017). https://doi.org/10.1109/ICTER.2017.8257810

19. Márquez, J.O.Á., Ziegler, J.: Augmented-reality-enhanced product comparison in physical retailing. In: Alt, F., Bulling, A., Döring, T. (eds.) Mensch und Computer 2019 - Tagungsband, pp. 55-65. The Association for Computing Machinery, Inc., New York (2019). https://doi. org/10.1145/3340764.3340800

20. Flavián, C., Ibáñez-Sánchez, S., Orús, C.: The impact of virtual, augmented and mixed reality technologies on the customer experience. J. Bus. Res. 100, 547-560 (2019). https://doi.org/ 10.1016/j.jbusres.2018.10.050

21. Furlan, R.: The future of augmented reality: Hololens - Microsoft's AR headset shines despite rough edges [Resources_Tools and Toys]. IEEE Spectr. 53, 21 (2016). https://doi.org/10.1109/ MSPEC.2016.7473143

22. Parise, S., Guinan, P.J., Kafka, R.: Solving the crisis of immediacy: how digital technology can transform the customer experience. Bus. Horiz. 59, 411-420 (2016). https://doi.org/10. 1016/j.bushor.2016.03.004

23. Mora, D., Jain, S., Nalbach, O., Werth, D.: Holographic recommendations in brick-and-mortar stores. In: AMCIS 2020 Proceedings (2020)

24. Fuchs, K., Grundmann, T., Fleisch, E.: Towards identification of packaged products via computer vision. In: Proceedings of the 9th International Conference on the Internet of Things, pp. 1-8. ACM, New York (10222019). https://doi.org/10.1145/3365871.3365899

25. Cheng, K., Nakazawa, M., Masuko, S.: MR-Shoppingu: physical interaction with augmented retail products using continuous context awareness. In: Munekata, N., Kunita, I., Hoshino, J. (eds.) ICEC 2017. LNCS, vol. 10507, pp. 452-455. Springer, Cham (2017). https://doi.org/ 10.1007/978-3-319-66715-7_61

26. Venkatesh, V., Aloysius, J.A., Burton, S.: Design and evaluation of auto-ID enabled shopping assistance artifacts in customers' mobile phones: two retail store laboratory experiments. MISQ 41, 83-113 (2017). https://doi.org/10.25300/MISQ/2017/41.1.05

27. Loureiro, S.M.C., Breazeale, M.: Pressing the buy button. Cloth. Text. Res. J. 34, 163-178 (2016). https://doi.org/10.1177/0887302X16633530

28. Verhoef, P.C., Lemon, K.N., Parasuraman, A., Roggeveen, A., Tsiros, M., Schlesinger, L.A.: Customer experience creation: determinants, dynamics and management strategies. J. Retail. 85, 31-41 (2009). https://doi.org/10.1016/j.jretai.2008.11.001

29. Juaneda-Ayensa, E., Mosquera, A., Sierra Murillo, Y.: Omnichannel customer behavior: key drivers of technology acceptance and use and their effects on purchase intention. Front. Psychol. 7, 1117 (2016). https://doi.org/10.3389/fpsyg.2016.01117 
30. Peukert, C., Pfeiffer, J., Meissner, M., Pfeiffer, T., Weinhardt, C.: Acceptance of imagined versus experienced virtual reality shopping environments: insights from two experiments. Research Papers (2019)

31. Roy, S.K., Balaji, M.S., Sadeque, S., Nguyen, B., Melewar, T.C.: Constituents and consequences of smart customer experience in retailing. Technol. Forecast. Soc. Chang. 124, 257-270 (2017). https://doi.org/10.1016/j.techfore.2016.09.022

32. Poushneh, A., Vasquez-Parraga, A.Z.: Discernible impact of augmented reality on retail customer's experience, satisfaction and willingness to buy. J. Retail. Consum. Serv. 34, 229-234 (2017). https://doi.org/10.1016/j.jretconser.2016.10.005

33. Intention to Use Digital Banking Services of Young Retail Customers in Vietnam (2021)

34. Deepthi, P.M., Purna, G.V.: Evolution of E-commerce in indian retail market and its future trends. In: Dynamic Business Trends and Innovations in Contemporary Times. Para-manount Publishing, pp. 162-168 (2021)

35. Reimann, O., Thomas, O., Kucza, G., Schuppisser, S.: First insights on brand attitude towards a retailer's individual private labels. In: Martínez-López, F.J., Gázquez-Abad, J.C. (eds.) NBPL 2021. SPBE, pp. 20-23. Springer, Cham (2021). https://doi.org/10.1007/978-3-030-769 35-2_3

36. Ungureanu, D., et al.: HoloLens 2 Research Mode as a Tool for Computer Vision Research (2020)

37. PTC, Inc.: Vuforia - Engine (2020). https://engine.vuforia.com/engine

38. Microsoft: Mixed Reality Toolkit (2020). https://microsoft.github.io/MixedRealityToolkitUnity/README.html

39. Forman, C., Ghose, A., Wiesenfeld, B.: Examining the relationship between reviews and sales: the role of reviewer identity disclosure in electronic markets. Inf. Syst. Res. 19(3), 291-313 (2008). https://doi.org/10.1287/ISRE.1080.0193

40. Pu, P., Chen, L., Hu, R.: A user-centric evaluation framework for recommender systems. In: Mobasher, B. (ed.) Proceedings of the Fifth ACM Conference on Recommender Systems. ACM Digital Library, p. 157. ACM, New York (2011). https://doi.org/10.1145/2043932.204 3962

41. Huddleston, P.T., Behe, B.K., Driesener, C., Minahan, S.: Inside-outside: using eye-tracking to investigate search-choice processes in the retail environment. J. Retail. Consum. Serv. 43, 85-93 (2018). https://doi.org/10.1016/j.jretconser.2018.03.006

42. Shankar, V., Inman, J.J., Mantrala, M., Kelley, E., Rizley, R.: Innovations in shopper marketing: current insights and future research issues. J. Retail. 87, S29-S42 (2011). https://doi.org/ 10.1016/j.jretai.2011.04.007

Open Access This chapter is licensed under the terms of the Creative Commons Attribution 4.0 International License (http://creativecommons.org/licenses/by/4.0/), which permits use, sharing, adaptation, distribution and reproduction in any medium or format, as long as you give appropriate credit to the original author(s) and the source, provide a link to the Creative Commons licence and indicate if changes were made.

The images or other third party material in this chapter are included in the chapter's Creative Commons licence, unless indicated otherwise in a credit line to the material. If material is not included in the chapter's Creative Commons licence and your intended use is not permitted by statutory regulation or exceeds the permitted use, you will need to obtain permission directly from the copyright holder. 